\title{
DISTRIBUIÇÃO ESPACIAL DA PRECIPITAÇÃO NA BACIA HIDROGRÁFICA DO RIO XINGU
}

\author{
SANTOS, Cleber Assis dos ${ }^{1}$ \\ LIMA, Aline Maria Meiguins de ${ }^{2}$ \\ FRANCO, Vania dos Santos ${ }^{2}$ \\ ARAUJO, Ivinny Barros de ${ }^{2}$ \\ MENEZES, José Felipe Gazel ${ }^{2}$ \\ GOMES, Naiana Milena Oliveira ${ }^{2}$
}

RESUMO: A necessidade de entender a variabilidade da distribuição espacial da precipitação pluviométrica é de extrema importância para o desenvolvimento e planejamento na gestão dos recursos hídricos. A caracterização tem grande aplicação como indicador para previsão do grau de vulnerabilidade da bacia a fenômenos como enchentes, inundações, dentre outros. O rio Xingu, formado pela confluência dos rios Culuene e Sete de Setembro, ambos procedentes da Serra do Roncador, tem suas nascentes com extensão de $2.271 \mathrm{~km}$ até sua foz, no rio Amazonas, que está na cota 3 a 4 m. Sua bacia tem direção S-N e ocupa uma área total de $509.685 \mathrm{~km}^{2}$. O objetivo deste trabalho é expor as características hidrológicas da bacia hidrográfica do rio Xingu. De acordo com a série histórica (1985 até 2013) de dados, observou-se que para a bacia do rio Xingu a precipitação anual média é de 1963,5 mm. O baixo curso concentra os máximos de precipitação, superiores a $2200 \mathrm{~mm}$, caracterizando nesta região o maior potencial hídrico da bacia.

Palavras-chave: Amazônia. Hidrologia. Potencial hídrico.

SUMMARY: The need to understand the variability of the spatial distribution of rainfall is extremely important for the development and planning in the Management of Water Resources. The characterization has wide application as an indicator to predict the degree of vulnerability of the basin before phenomena such as floods, inundations and others. The Xingu River, formed by the confluence of the rivers Culuene and Sete de Setembro, both coming from the Serra do Roncador, has its source with a length of $2.271 \mathrm{~km}$ to its mouth in the Amazon River, whose quota is 3 to $4 \mathrm{~m}$. Its basin has $\mathrm{S}-\mathrm{N}$ direction and occupies a total area of $509.685 \mathrm{~km}^{2}$. The objective of this work is to expose the hydrological characteristics of the Xingu River Basin. According to the historical series data (1985 to 2013), it was observed that the Xingu River basin has Average Annual Precipitation of 1963,5 mm. The lower course concentrates the maximum precipitation, exceeding $2200 \mathrm{~mm}$, characterizing the highest hydropower potential of the basin in this region.

Keywords: Amazon. Hydrology. Water potential.

\section{INTRODUÇÃO}

A bacia hidrográfica do rio Xingu está situada dentro dos Estados do Pará e do Mato Grosso e abrange cerca de 509,7 mil km², onde o rio Xingu é o seu principal curso d'água. Representa um dos principais contribuintes da margem direita do rio Amazonas, tendo em torno de 60\% de seu território recoberto por áreas protegidas (unidades de conservação e terras indígenas) (VILLAS-BÔAS et al., 2012). No Estado do Pará, compõe junto com as bacias dos rios Tapajós e Tocantins, o conjunto de bacias federais (que pertencem a mais de um Estado) que drenam mais de 50\% do território paraense.

Outro fator que demonstra a importância da bacia é seu aproveitamento energético, atualmente discutido a partir da construção do reservatório de Belo Monte, que teve seu dimensionamento reduzido de

\footnotetext{
${ }^{1}$ Mestrando em Meteorologia Aplicada (UFV)

${ }^{2}$ Universidade Federal do Pará
} 
1.225 para $440 \mathrm{~km}^{2}$ (11.181 MW), colocando o reservatório principal (o "Reservatório da Calha") a montante da confluência do rio Bacajá (FEARNSIDE, 2006).

A bacia hidrográfica é uma área de captação natural de água da precipitação que faz convergir os escoamentos para um único ponto de saída, o exutório (CHRISTOFOLETTI, 2006). De acordo com Pinto et al., (2011), bacia hidrográfica é a área geográfica coletora de água de chuva que escoa pela superfície do solo.

A realização de estudos hidrológicos em bacias hidrográficas vem da necessidade de se compreender o funcionamento do balanço hídrico, dos processos que controlam o movimento da água e os impactos de mudanças do uso da terra sobre a quantidade e qualidade da água (WHITEHEAD; ROBINSON, 1993). A caracterização tem grande aplicação como indicador para previsão do grau de vulnerabilidade da bacia a fenômenos como enchentes, inundações e erodibilidade, dentre outros (CARDOSO et al., 2006; VILLELA; MATTOS, 1975), além de ser uma informação que auxilia na compreensão dos eventos pluviais e suas consequências (VENTURA, 2011).

A necessidade de entender a variabilidade da distribuição espacial da precipitação pluviométrica é de extrema importância para o desenvolvimento e planejamento na gestão dos recursos hídricos, permitindo compreender a oferta hídrica da bacia e quanto pode fornecer para o aproveitamento, em termos de usos múltiplos, e assim evitar situações de escassez local (seja qualitativa ou quantitativa) (LUCAS et al., 2009).

Para Bertoni e Tucci (2001), a disponibilidade de precipitação numa bacia durante o ano é fator determinante para quantificar, entre outros, a necessidade de irrigação e o abastecimento de água doméstico e industrial. Segundo Machado et al., (2010), as chuvas influenciam na infraestrutura e nos recursos naturais dentro das cidades. A precipitação pluviométrica é um dos elementos mais irregulares espacial e temporalmente, causando impactos em diversas atividades humanas (MIRANDA; PEREIRA, 2011).

Diante do exposto, este trabalho objetiva estudar a distribuição espacial da precipitação pluviométrica na bacia hidrográfica do rio Xingu, definindo assim as áreas de maior e menor potencial em termos de oferta hídrica.

\section{MATERIAL E MÉTODO}

\section{Área de estudo e dados}

O rio Xingu, formado pela confluência dos rios Culuene e Sete de Setembro, ambos procedentes da Serra do Roncador, tem suas nascentes com extensão de $2.271 \mathrm{~km}$ até sua foz, no rio Amazonas, que está na cota 3 a $4 \mathrm{~m}$. Sua bacia tem direção $\mathrm{S}-\mathrm{N}$ e ocupa uma área total de $509.685 \mathrm{~km}^{2}$, que corresponde a 46 municípios do Mato Grosso e 42 municípios do Pará. Seus principais afluentes são (de montante para jusante) o Suiá-Miçu, Auaiá-Miçu, Comandante Fontoura, Fresco e Bacajá pela margem direita; e Curisevo, Pardo, Iriri e Acarai, pela margem esquerda (Figura 01). A bacia do Iriri destaca-se pelo porte, com uma área de drenagem de $142.082 \mathrm{~km}^{2}$. 
Figura 01 - Distribuição geográfica da bacia hidrográfica de rio Xingu.



Fonte: Autor.

Adotou-se a definição das sub-bacias hidrográficas, empregando os limites já definidos (traçados) pelo Sistema Ottobacias (Resolução n. 30/2002 do Conselho Nacional de Recursos Hídricos), nas "Ordens 2 e 3". Os dados pluviométricos (chuva) foram obtidos a partir do banco de dados históricos disponibilizados pela Agência Nacional de Águas (ANA), por meio de estações de coleta em diversos pontos da bacia do rio Xingu e entorno, sendo aproveitado apenas as estações com dados consistentes (menor número de falhas), compreendendo 32 estações pluviométricas (Figura 02) com a série histórica de 1985 a 2013.

Figura 02 - Localização das estações pluviométricas.

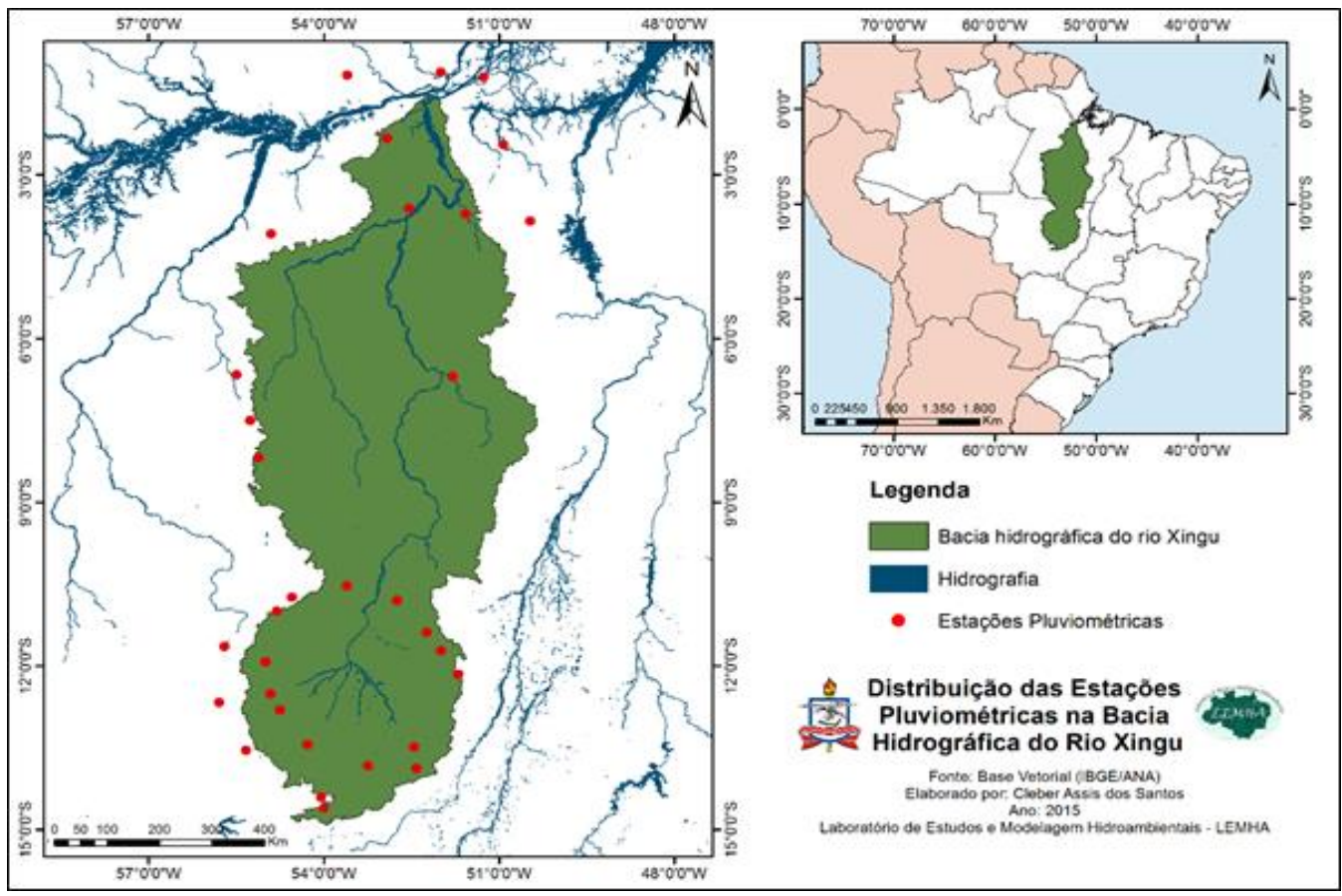

Fonte: Autor. 


\section{Preenchimento de falhas}

Utilizando o Software Hidro 1.2 da ANA, foram exportados os dados hidrológicos para a planilha eletrônica Microsoft Excel 2013, onde foram identificadas algumas falhas e corrigidas.

O preenchimento de falhas pluviométricas (32 estações) foi obtido através do método de ponderação regional (Equação 1). Utilizado normalmente para o preenchimento de séries mensais ou anuais de precipitações, visando homogeneização do período de informações e a análise estatística das precipitações (BERTONI; TUCCI, 2001). São utilizadas no mínimo três estações pluviométricas próximas da estação com falhas com o mínimo de dez anos de dados.

$$
P(x)=\frac{\mathrm{Mx}}{\mathrm{Ma}} P a+\frac{\mathrm{Mx}}{\mathrm{Mb}} P b+\frac{\mathrm{Mx}}{\mathrm{Mc}} P c+\cdots+\frac{\mathrm{Mx}}{\mathrm{Mn}} P n
$$

Esta equação nos diz que a observação na estação que existe a falha é proporcional as observações nas estações vizinhas $\mathrm{A}, \mathrm{B}, \mathrm{C}, \ldots, \mathrm{N}$ em um período corrente. Onde, Mx é a média das observações da estação principal, ou seja, a que possui as falhas nos períodos que existem observações em outras estações; $\mathrm{Ma}, \mathrm{Mb}, \mathrm{Mc}, \ldots \mathrm{Mn}$, são as medidas das estações suplementares para o período comum à estação principal; $\mathrm{Pa}, \mathrm{Pb}, \mathrm{Pc}, \ldots, \mathrm{Pn}$, são as observações nas estações suplementares no período comum da estação principal (com falhas).

\section{RESULTADOS E DISCUSSÃO}

De acordo com a série histórica de dados, observou-se que para a bacia do rio Xingu a precipitação anual média é de 1963,5 mm. Os menores valores de precipitação, encontram-se na região da nascente da bacia hidrográfica e ao Leste (média de 1782,3 mm) e os maiores valores, encontram-se na região da foz e ao Oeste (média de 2426,7 mm) (Figura 03).

Figura 03 - Média anual acumulada da precipitação pluviométrica.

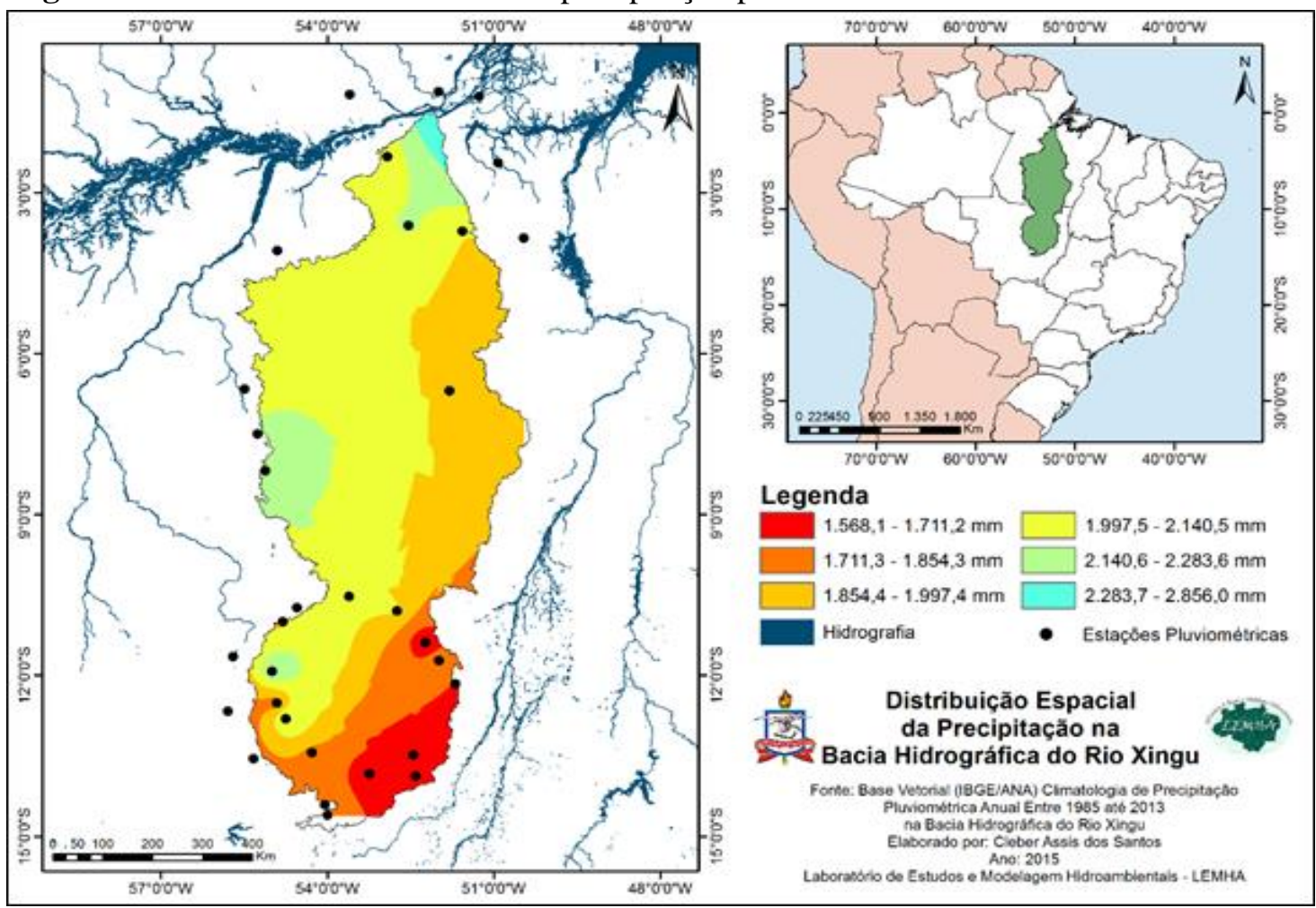

Fonte: Autor. 
Os anos de 1985, 1988 e 1989 houveram as maiores ocorrências de precipitação (média aritmética de 2185,0 mm/ano) e 1987, 1997, 1998 e 2007 os anos menos chuvosos (média aritmética de 1732,1 mm/ano), estes períodos coincidem respectivamente com as influências dos fenômenos de La Niña e El Niño na região Amazônica (CENTRO DE PREVISÃO DE TEMPO E ESTUDOS CLIMÁTICOS, 2014), assim como identificado por Franco et al. (2015), que comprovou que em anos de La Niña as respostas fluviométricas na cidade de Altamira - PA, são mais elevadas quando comparado aos anos El Niño, onde os valores fluviométricos são menos intensos.

Durante o período observado, a precipitação pluviométrica se concentrou entre os meses de novembro e abril (1541 mm). Por outro lado, entre os meses de maio a outubro, as chuvas têm menor intensidade (estação menos chuvosa na Amazônia), onde a média acumulada nesse período foi de $422 \mathrm{~mm}$ (Figura 04).

Figura 04 - Média mensal acumulada da precipitação pluviométrica.

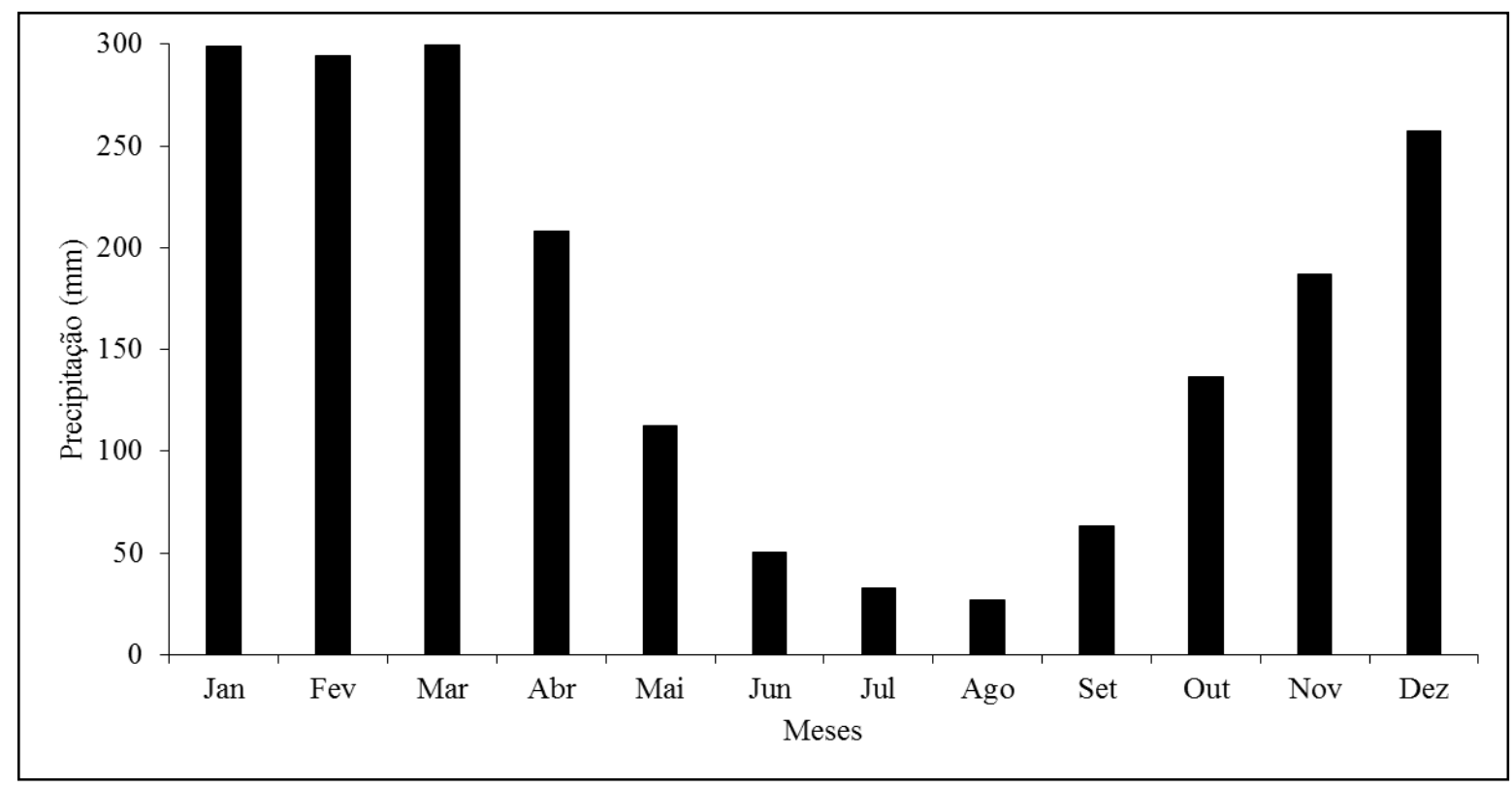

Fonte: Autor.

A figura 05, mostra a sazonalidade média mensal da distribuição espacial de precipitação pluviométrica acumulada. Ao acompanhar a variabilidade mensal da pluviosidade da bacia hidrográfica do rio Xingu, observa-se a influência de sistemas meteorológicos de escala sinótica e global que atuam na região amazônica. Dentre os sistemas, destacam-se dois principais: a ZCIT (Zona de Convergência Intertropical) e a ZCAS (Zona de Convergência do Atlântico Sul). Esses dois sistemas meteorológicos são fundamentais para definir a climatologia da região, elevando a precipitação na sua área de atuação.

A ZCIT atua diretamente na precipitação da região Norte do Brasil (REBOITA et al., 2010). Segundo Nobre et al. (2000), em anos chuvosos, o posicionamento da ZCIT pode atingir até $5^{\circ}$ a $6^{\circ}$ de latitude Sul. Carvalho (2011), aponta que a ZCIT está na sua posição mais austral nos meses de março e abril. 
Figura 05 - Distribuição espacial da média mensal acumulada da precipitação pluviométrica.

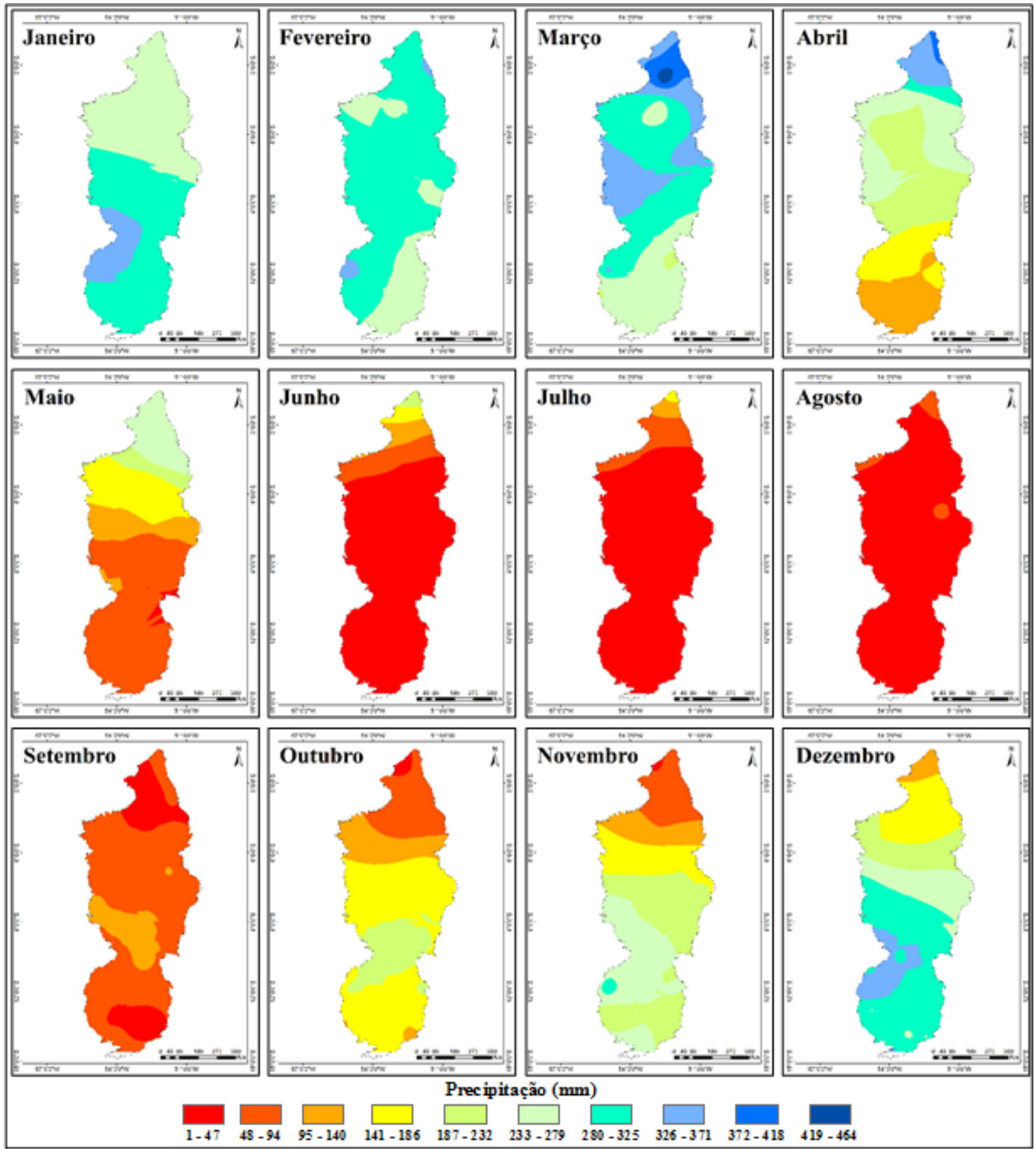

Fonte: Autor.

Segundo Quadro et al. (2012), a ZCAS atua principalmente nos meses de verão (21 de dezembro a 21 de março) no Hemisfério Sul, elevando os índices pluviométricos sobre a região de atuação. Climatologicamente, este fenômeno atua na América do Sul no sentido noroeste leste (NW-SE), se estendendo do Sul da Amazônia até o Sudeste do Brasil; tem atuação entre as regiões centro-oeste e sudeste do Brasil entre os meses de outubro a abril (primavera/verão estendido), gerando grande quantitativo de precipitação praticamente em todos os anos (CARVALHO; JONES, 2009).

Os resultados obtidos pela análise conjunta da distribuição da precipitação pluviométrica, demonstram que há dois principais sistemas meteorológicos precipitantes, que atuam no Xingu, um aproximadamente entre os meses de outubro a fevereiro (ZCAS) na região Sul da bacia hidrográfica e 
outro aproximadamente entre os meses de março a maio (ZCIT) ao norte do rio Xingu, seguindo para a jusante da bacia hidrográfica. Nos meses entre abril a setembro, o sul da bacia hidrográfica, apresenta baixa pluviosidade, mostrando que nesse período, climatologicamente, há pouca atividade de sistemas meteorológicos precipitantes.

\section{CONCLUSÃO}

Compreender o potencial em termos de oferta hídrica de uma bacia hidrográfica é de fundamental importância, principalmente para poder subsidiar a tomada de decisões futuras.

A distribuição espacial da precipitação na bacia do rio Xingu mostrou que umas das áreas que apresentam resultados mais significativos em termos de oferta hídrica é a região Baixo Xingu, onde concentram-se os máximos de precipitação, superiores a $2200 \mathrm{~mm}$, caracterizando nesta região maior potencial hídrico da bacia.

No médio curso, a precipitação é mais concentrada na porção ocidental do que na oriental, porém é capaz de atingir os valores máximos definidos para a bacia, superiores a $2000 \mathrm{~mm}$ acumulados durante o ano, indicando potencial hídrico entre "Moderado e Moderado a Alto". No alto curso a precipitação gira em torno de 1566,1 a 1997,4 mm, anuais acumulados, caracterizando potencial hídrica "Moderado a Baixo".

\section{REFERÊNCIAS}

BERTONI, J. C.; TUCCI, C. E. M. Precipitação. In: TUCCI, C. E. M. (Org.). Hidrologia: ciência e aplicação. Porto Alegre: UFRGS/ABRH, 2001. p. 177-241.

CARDOSO, C. A.et al. Caracterização morfométrica da bacia hidrográfica do rio Debossan, Nova Friburgo, RJ. Revista Árvore, v. 30, n. 2, p. 241-248, 2006.

CARVALHO, M. A. V. Variabilidade da largura e intensidade da zona de convergência intertropical atlântica: aspectos observacionais e de modelagem. 2011. 154 f. Instituto Nacional de Pesquisas Espaciais, Dissertação (Mestrado em Meteorologia), São José dos Campos, 2011.

CARVALHO, L. M. V.; JONES, C. Zona de Convergência do Atlântico Sul. In: CAVALCANTI, I. F. A. (Org.). Tempo de clima no Brasil. São Paulo: Oficina de textos, 2009. p. 95-125.

CHRISTOFOLETTI, A. Geomorfologia fluvial. In: CHRISTOFOLETTI, A. (Org.). Geomorfologia, São Paulo: Edgard Blucher, 2006. p. 52-78.

CENTRO DE PREVISÃO DE TEMPO E ESTUDOS CLIMÁTICOS (CPTEC). El Niño e La Niña. Disponível em: $<$ http://enos.cptec.inpe.br $>$. Acesso em: 10 dez. 2014.

FEARNSIDE, P. M. Dams in the Amazon: Belo Monte and Brazil's Hydroelectric Development of the Xingu River Basin. Environmental Management, v. 38, n. 1, p. 16-27, 2006.

FRANCO, V. S.et al. Evolução mensal da cota fluviométrica do Rio Xingu em Altamira-PA associada aos eventos El Niño e La Niña. Ciência e Natura, v. 37, ed. especial SIC, p. 104-10, 2015.

LUCAS, E. W. M.et al. Modelagem hidrológica determinística e estocástica aplicada à região hidrográfica do Xingu - Pará. Revista Brasileira de Meteorologia, v. 24, n. 3, p. 308-322, 2009. 
MACHADO, R. L.et al. Spatial variability of maximum annual daily rain under different return periods at the Rio de Janeiro State, Brazil. Bragantia, v. 69, supl. p. 77-84, 2010.

MIRANDA, R. A. C.; PEREIRA, F. R. Desenvolvimento de plataforma para monitoramento automatizado de dados termo-pluviométricos. Geosul (UFSC), v. 26, n. 52, p. 129-144, 2011.

NOBRE, P.et al. Estudo climatológico da cosição da ZCIT no Atlântico Equatorial e sua influência sobre o Nordeste do Brasil. In: CONGRESSO BRASILEIRO DE METEOROLOGIA, 11., 2000. Rio de Janeiro. Anais... Rio de Janeiro: SBMET, 2000. p. 1142-1147.

PINTO, N. L. S.et al. Hidrologia básica. São Paulo: Edgard Blücher, 2011. 278p.

REBOITA, M. S.et al. Regimes de precipitação na América do Sul: uma revisão bibliográfica. Revista Brasileira de Meteorologia, v. 25, n. 2, p. 185-204, 2010.

QUADRO, M. F. L.et al. Análise climatológica da precipitação e do transporte de umidade na região da ZCAS através da nova geração de reanálises. Revista Brasileira de Meteorologia, v. 27, n. 2, p. 152-162, 2012.

VENTURA, R. M. G. Caracterização ambiental e hidrológica da Bacia do Córrego do Barbado em Cuiabá-MT. 2011. 112 f. Universidade Federal do Mato Grosso, Dissertação (Mestrado em Engenharia de Edificações e Ambiental), Faculdade de Arquitetura, Engenharia e Ambiental, Cuiabá, 2011.

VILLELA, S.M.; MATTOS, A. Hidrologia aplicada. São Paulo: McGraw-Hill do Brasil, 1975. 245 p.

VILLAS-BÔAS, A. (Org). De olho na bacia do Xingu. São Paulo: Instituto Socioambiental. 2012. 61 p.

WHITEHEAD, P. G.; ROBINSON, M. Experimental basin studies: an international and historic perspective of forest impacts. Journal de Hydrology, v. 145, n. 3-4, p. 217-230, 1993. 